\title{
Studies Toward the Pharmacophore of Salvinorin A, a Potent Kappa Opioid Receptor Agonist
}

\author{
Thomas A. Munro ${ }^{\dagger}$, Mark A. Rizzacasa ${ }^{\star}, \dagger$, Bryan L. Roth $\ddagger$, Beth A. Toth ${ }^{\ddagger}$, and Feng Yan $\ddagger$ \\ School of Chemistry, The University of Melbourne, Victoria, 3010, Australia; National Institute of \\ Mental Health Psychoactive Drug Screening Program and Department of Biochemistry, Case \\ Western Reserve University Medical School, Cleveland, OH 44106 \\ tSchool of Chemistry, The University of Melbourne. \\ ‡NIMH PDSP and Department of Biochemistry, Case Western Reserve University Medical School.
}

\begin{abstract}
Salvinorin A (1), from the sage Salvia divinorum, is a potent and selective kappa opioid receptor (KOR) agonist. We screened other salvinorins and derivatives for binding affinity and functional activity at opioid receptors. Our results suggest that the methyl ester and furan ring are required for activity, but that the lactone and ketone functionalities are not. Other salvinorins showed negligible binding affinity at the KOR. None of the compounds bound to mu or delta opioid receptors.
\end{abstract}

Salvinorin A (1) ${ }^{1}$ was isolated from Salvia divinorum, a traditional medicine of the Mazatec Indians of Oaxaca, Mexico. Infusions of the leaves induce visions, and $\mathbf{1}$ is a potent hallucinogen in humans. ${ }^{2} \mathbf{1}$ is a selective agonist at the $\kappa$ opioid receptor (KOR), ${ }^{3}$ with comparable potency and efficacy to the synthetic KOR agonists U50488 and U69593. ${ }^{4}$ KOR ligands appear to have therapeutic potential against a range of conditions, including pain, ${ }^{5}$ nausea, ${ }^{6}$ depression, ${ }^{7}$ and HIV infection. ${ }^{8} \mathbf{1}$ is the only non-nitrogenous KOR agonist known, with no structural similarity to other such compounds. ${ }^{3}$ Given this, $\mathbf{1}$ represents a valuable lead for the development of more potent and selective KOR ligands. At present, little is known of the compound's structure-activity relationships. The deacetyl compound salvinorin B (2), also isolated from S. divinorum ${ }^{9}$ is inactive at the KOR, while substitution of more hindered esters at the 2-position reduces or abolishes activity. ${ }^{4}$ To probe the importance of other functional groups in $\mathbf{1}$, we set out to test related compounds from this plant, as well as semisynthetic derivatives of $\mathbf{1}$, for binding affinity and functional activity at cloned opioid receptors.

Salvinorins A (1), D (4), and E (5) were isolated as described previously. ${ }^{10}$ Acetylation of 4 gave salvinorin C (6). ${ }^{11}$ The known $1 \alpha$-hydroxy derivative $\mathbf{8}^{9,12 a}$ and diacetate $9^{11}$ were prepared by published procedures (Figure 1).

A number of new derivatives of $\mathbf{1}$ were also synthesized, and the structures verified by NMR analysis, including DEPT, COSY, HMQC, HMBC and nOe experiments. As a preliminary step, 1 itself was reexamined using these techniques. This confirmed the original ${ }^{1} \mathrm{H}$ and ${ }^{13} \mathrm{C}$ assignments (based on decoupling experiments) ${ }^{9}$ in all cases except the overlapping multiplets of H-6 and H-7. The HMQC spectrum showed crosspeaks from C-6 ( $\delta 38.1 \mathrm{ppm})$ to multiplets

*Corresponding author. Tel: +61-3-8344-6488. Fax: +61-3-9347-5180. E-mail: masr@unimelb.edu.au..

Supporting Information Available: Experimental procedures, characterization data, ${ }^{1} \mathrm{H}$ and ${ }^{13} \mathrm{C}$ NMR spectra, and IUPAC/NIST Chemical Identifiers (INChIs) of the target compounds (the spectra of $\mathbf{4}$ and $\mathbf{5}$ were published previously). ${ }^{10}$ This material is available free of charge via the Internet at http://pubs.acs.org. 
at $\delta 1.57 \& 1.78 \mathrm{ppm}$, and from C-7 $(\delta 18.1 \mathrm{ppm})$ to $\delta 1.63 \& 2.15 \mathrm{ppm}$ (see the Experimental Section for the revised assignments).

Until recently, no satisfactory procedure for deacetylation of $\mathbf{1}$ had been published. Brown reported that $\mathrm{KCN}$ in refluxing MeOH/THF gave $\mathbf{2}$ in quantitative yield, ${ }^{13 a}$ but in our hands 8-epi-2 was the major product. Additionally, the epimers were not resolved on silica using Brown's solvent system ( $3 \% \mathrm{MeOH} / \mathrm{CH}_{2} \mathrm{Cl}_{2}$ ). These problems have recently been overcome by Prisinzano and coworkers. ${ }^{14}$ Using their conditions (a suspension of 1 and $\mathrm{Na}_{2} \mathrm{CO}_{3}$ in $\mathrm{MeOH}$ ), we detected only a trace of 8-epi-2, which was removed by trituration in $\mathrm{MeOH}$, giving 2 in 76\% yield without chromatography. Koreeda and coworkers have on several occasions proposed a complex mechanism for this epimerization, involving cleavage of the C-8/9 bond. $9,13 \mathrm{~b}, 15 \mathrm{We}$ see no reason to look beyond enolate formation, followed by protonation from the opposite face.

8-epi-Salvinorin A (8-epi-1), previously reported without experimental detail or characterization data, ${ }^{16}$ was formed by treatment of 1 with $\mathrm{NaHCO}_{3}$ in dry DMPU or DMF at $150{ }^{\circ} \mathrm{C}$ (addition of water caused deacetylation). In commercial DMPU (98\% purity) the $\mathrm{NaHCO}_{3}$ could be omitted, presumably due to a basic impurity; heating in distilled DMPU alone gave no reaction. The configuration of 8-epi-1 was apparent from the lack of a diaxial coupling constant for H-8 (dd, 5.0 \& $2.2 \mathrm{~Hz}$, compared to 11.6 \& $3.1 \mathrm{~Hz}$ in $\mathbf{1}$ ). Also, irradiation of $\mathrm{H}-12$ gave a strong nOe enhancement of $\mathrm{H}-8$. The corresponding experiment on 1 gave an enhancement of H-20, but not $\mathrm{H}-8$.

The formate (3) was prepared from 2 using formic acid/acetic anhydride mixture. ${ }^{17}$ NMR assignments were inferred from the near-identical spectra of $\mathbf{1}$. Tetrahydrosalvinorin A (10) was synthesised by hydrogenation of $\mathbf{1}$, using rhodium catalyst to minimise the hydrogenolysis of the lactone caused by palladium (Scheme 1). ${ }^{9}$ For characterization, one epimer was separated by HPLC. By ${ }^{1} \mathrm{H}$ NMR, H-12 showed a new coupling to H-13, but its coupling constants to H-11 were scarcely affected, suggesting little change of conformation in the lactone. 17Deoxysalvinorin A (12) was synthesised by deoxygenation of known lactol $\mathbf{1 1}^{13 \mathrm{c}}$ using $\mathrm{Et}_{3} \mathrm{SiH}$ and $\mathrm{BF}_{3} \cdot \mathrm{Et}_{2} \mathrm{O} .{ }^{18} \mathrm{By}{ }^{1} \mathrm{H} \mathrm{NMR}$, the $\mathrm{H}-17$ oxymethylene appeared as a doublet, $\delta 3.58$, coupling to $\mathrm{H}-8$ (COSY crosspeak). As with 1, irradiation of $\mathrm{H}-12$ gave a strong nOe enhancement of $\mathrm{H}-20$ rather than $\mathrm{H}-8$, confirming the configuration at C-8. The enol ether (13) was also formed as byproduct. An attempted alternative route to 12, using Amberlyst 15 resin, ${ }^{19}$ instead gave 13 in $76 \%$ yield. Indeed, 11 proved extremely prone to elimination; storage overnight in $\mathrm{CDCl}_{3}$ at $-20{ }^{\circ} \mathrm{C}$ gave $52 \%$ yield of 13 , presumably catalyzed by $\mathrm{DCl}$. The quaternary C-8 peak ( $\delta 117.0 \mathrm{ppm}$ ) of $\mathbf{1 3}$ showed HMBC correlations to H-6, -7 and -17. A long range coupling $(1.8 \mathrm{~Hz})$ was evident between one of the $\mathrm{H}-7$ protons and $\mathrm{H}-17$.

Formation of the 18-hydroxy derivative $\mathbf{1 5}$ proved challenging (Scheme 2). We decided to proceed via borane reduction of the acid $\mathbf{1 4}$; given the base-sensitivity of $\mathbf{1}$, the acid would be derived by nucleophilic cleavage of the methyl ester. Of many procedures tried, only lithium ethanethiolate (LiSEt) in DMPU proved satisfactory. This was based on a published procedure (LiSMe in HMPA), ${ }^{20}$ modified to avoid the use of methanethiol (intense odor) and HMPA (carcinogen). Using LiSEt, ester cleavage was accompanied by deacetylation; standard acetylation conditions gave the acid $\mathbf{1 4}$ in good yield as an inseparable mixture of 8-epimers (methylation of a small portion with $\mathrm{CH}_{2} \mathrm{~N}_{2}$ in $\mathrm{Et}_{2} \mathrm{O} / \mathrm{CH}_{2} \mathrm{Cl}_{2}$ at $0{ }^{\circ} \mathrm{C}$ gave a mixture of $\mathbf{1}$ and 8-epi-1 by TLC and ${ }^{1} \mathrm{H}$ NMR). The acid mixture was then treated with $\mathrm{BH}_{3} \bullet \mathrm{THF}$ at $55{ }^{\circ} \mathrm{C}$, giving the desired alcohol 15 in low yield (23\%), along with its 8-epimer. The COSY spectrum of 15 showed a crosspeak between the complex H-4 multiplet ( $\delta 1.89 \mathrm{ppm})$ and the diastereotopic H-18 oxymethylene ( $\delta 3.94 \& 3.49 \mathrm{ppm})$. The chemical shifts and coupling constants for $\mathrm{H}-8$ and $\mathrm{H}-12$ were near-identical to those of $\mathbf{1}$, and irradiation of $\mathrm{H}-12$ gave a strong nOe enhancement of $\mathrm{H}-20$ rather than $\mathrm{H}-8$, confirming the configuration at $\mathrm{C}-8$. 
Deoxygenation of the ketone (to give 18) was also challenging. The two-step route via hydride reduction of a tosylhydrazone was attempted, but $\mathbf{1}$ proved unreactive towards tosylhydrazide under a range of conditions, including sonication and microwave irradiation. We therefore decided to reduce the ketone prior to deoxygenation. The standard approaches to hydroxyl deoxygenation, involving hydride reduction of sulfonate derivatives or radical reduction of thiocarbonyl derivatives, ${ }^{21}$ would require derivatization of the $1 \alpha$-hydroxyl group, which is extremely hindered and unreactive. For example, Valdés and coworkers found that acetylation of diol 7 gave 8 rather than diacetate 9,11 but overcame this obstacle by installing an orthoester between the two hydroxyl groups. We took an analogous approach to radical deoxygenation, employing the cyclic thionocarbonate 16. This was formed in high yield by the reaction of 7 with thiocarbonyldiimidazole in DMF. Since these conditions again caused epimerization, and the epimers were inseparable on silica gel, separation of the epimers of starting material 7 was superfluous. Under standard radical reduction conditions $\left(\mathrm{Bu}_{3} \mathrm{SnH}\right.$ and $\mathrm{AIBN}$ in toluene at 80 $\left.{ }^{\circ} \mathrm{C}\right),{ }^{22} \mathbf{1 6}$ then gave the separable deoxy compounds $\mathbf{1 7}$ and 8-epi-17 in $47 \%$ combined yield, along with a byproduct (presumably the 1-hydroxy regioisomer) which was not characterized due to contamination by tin compounds. Acetylation of $\mathbf{1 7}$ gave 1-deoxysalvinorin A (18). The $\mathrm{H}-2$ multiplet ( $\delta 4.74 \mathrm{ppm}$ ) showed the expected couplings to H-1 \& -3 (COSY), including two diaxial couplings $(11 \mathrm{~Hz})$.

The target compounds were screened in radioligand binding assays at cloned opioid receptors. None of the compounds showed significant binding to $\mu$ or $\delta$ opioid receptors at $1 \mu \mathrm{M}$; binding affinities at the KOR are listed in Table 1. Those with sub-micromolar affinity were also screened for functional activity using a calcium flux assay (see Supporting Information for details of all assays). Since hindered esters at the 2-position interfere with binding to the KOR, ${ }^{4}$ we suspected that the less-hindered formate 3 might prove more potent, but in fact both affinity and potency were lower; the acetoxy group is therefore the optimal alkyl chain length. Salvinorin C (6) showed negligible binding affinity compared to $\mathbf{1}$. Consistent with this, in recent human testing $\mathbf{6}$ showed no psychoactivity. ${ }^{23}$ Previously, however, a mixture of $\mathbf{1}$ and $\mathbf{6}$ showed significantly greater sedative activity in mice than pure $1 .{ }^{11} \mathrm{It}$ is possible that these compounds undergo some in vivo interaction not apparent in our assay; however, the mouse assay used appears to have been confounded. ${ }^{12 b}$ Salvinorins D (4) and E (5) were inactive in our binding assay. Since the remaining terpenoids isolated from $S$. divinorum ${ }^{10,24}$ lack the 2ester essential to binding, it appears that $\mathbf{1}$ is the sole KOR agonist present in the plant. Another implication of these results, along with the very low affinities of $\mathbf{8}$ and $\mathbf{9}$, is that reduction of the ketone to an $\alpha$-hydroxy or -acetoxy group dramatically reduces or abolishes binding affinity. This was surprising: molecular modelling indicated that this modification would not affect binding. ${ }^{3}$ Although the very low affinities of 5, 6, 8, and $\mathbf{9}$ might appear to suggest that the ketone is part of the pharmacophore, the relatively high affinity and potency of 1-deoxy compound 18 show that it is not. This suggests that a $1 \alpha$-hydroxy/acetoxy group interacts unfavourably with the KOR. Curiously, saturating the 3,4-double bond in 5 raises binding affinity (compare 8), but has the opposite effect in 6 (compare 9).

The substantially reduced affinities of 8-epi-1 and tetrahydro derivative $\mathbf{1 0}$ suggest that the furan ring is part of the pharmacophore, as predicted. ${ }^{3}$ However, the reduction in potency in the functional assay was far smaller, particularly in 10. These compounds represent relatively minor modifications of $\mathbf{1}$; more drastic modifications, less amenable to a semisynthetic approach, would be required to definitively resolve the role of the furan ring. By contrast, the predicted role of the methyl ester is strongly confirmed by the results for 18-hydroxy derivative 15; the compound appears to be an antagonist, since it binds but does not activate the receptor. Contrary to predictions, the high affinities of $\mathbf{1 1}, \mathbf{1 2}$, and $\mathbf{1 3}$ - all full agonists - show that the lactone carbonyl is not essential for binding or activity. However, the latter two compounds, especially 13, showed reduced potency in the functional assay. One possible explanation for inaccuracies in the initial model is differences in binding orientation between $\mathbf{1}$ and its 
derivatives; for instance, the 1-acetoxy group in $\mathbf{6}$ may serve as a poor substitute for the 2acetoxy group in $\mathbf{1}$.

In conclusion, our results indicate that $\mathbf{1}$ is the only compound from $S$. divinorum with significant affinity at the KOR. Other salvinorins show negligible affinity, and other compounds reported from the plant lack the features required for binding. In addition, we have tested at least one modification to every functional group in 1, and identified those not essential for binding to the KOR: namely, the lactone and ketone. This information should prove valuable in the development of selective KOR ligands, simplifying the design of synthetic analogs of 1. Compound $\mathbf{1 5}$ suggests that still further simplification may be possible, particularly in the development of KOR antagonists. It is also noteworthy that none of the target compounds bound to $\mu$ or $\delta$ opioid receptors. This suggests that, as a lead compound, 1 will withstand considerable modification without loss of selectivity. Finally, given the lack of structural similarity to other opioids, these results should be of value in modelling opioid receptors.

\section{Supplementary Material}

Refer to Web version on PubMed Central for supplementary material.

\section{Acknowledgments}

This work was supported by the NIMH PDSP and KO2MH01366 and RO1DA017204 (B.L.R.); the Melbourne University Research Grants Scheme (M.A.R.); and the Commonwealth Department of Education, Science and Training (T.A.M.).

\section{References}

1. Ortega A, Blount JF, Manchand PS. Salvinorin, a New trans-Neoclerodane Diterpene from Salvia divinorum (Labiatae). J. Chem. Soc., Perkin Trans. 1 1982:2505-2508.

2. Siebert DJ. Salvia divinorum and salvinorin A: New pharmacologic findings. J. Ethnopharmacol 1994;43:53-56. [PubMed: 7526076]

3. Roth BL, Baner K, Westkaemper R, Siebert D, Rice KC, Steinberg S, Ernsberger P, Rothman RB. Salvinorin A: A potent naturally occurring nonnitrogenous $\kappa$ opioid selective agonist. Proc. Natl. Acad. Sci. U.S.A 2002;99:11934-11939. [PubMed: 12192085]

4. Chavkin C, Sud S, Jin W, Stewart J, Zjawiony JK, Siebert DJ, Toth BA, Hufeisen SJ, Roth BL. Salvinorin A, an Active Component of the Hallucinogenic Sage Salvia divinorum Is a Highly Efficacious $\kappa$-Opioid Receptor Agonist: Structural and Functional Considerations. J. Pharmacol. Exp. Ther 2004;308:1197-1203. [PubMed: 14718611]

5. Delvaux M. Pharmacology and clinical experience with fedotozine. Expert Opin. Investig. Drugs 2001;10:97-110.

6. Kohl RL, MacDonald S. New pharmacologic approaches to the prevention of space/motion sickness. J. Clin. Pharmacol 1991;31:934-946. [PubMed: 1662231]

7. Ukai M, Suzuki M, Mamiya T. Effects of U-50,488H, a א-opioid receptor agonist, on the learned helplessness model of depression in mice. J. Neural Transm 2002;109:1221-1225. [PubMed: 12203050]

8. Lokensgard JR, Gekker G, Peterson PK. א-opioid receptor agonist inhibition of HIV-1 envelope glycoprotein-mediated membrane fusion and CXCR4 expression on $\mathrm{CD} 4^{+}$lymphocytes. Biochem. Pharmacol 2002;63:1037-1041. [PubMed: 11931835]

9. Valdés LJJ III, Butler WM, Hatfield GM, Paul AG, Koreeda M. Divinorin A, a Psychotropic Terpenoid, and Divinorin B from the Hallucinogenic Mexican Mint Salvia divinorum. J. Org. Chem 1984;49:4716-4720. We found that effective purification of 8 required pure starting diol 7 (HPLC in EtOAc). 
10. Munro TA, Rizzacasa MA. Salvinorins D-F, New Neoclerodane Diterpenoids from Salvia divinorum, and an Improved Method for the Isolation of Salvinorin A. J. Nat. Prod 2003;66:703-705. [PubMed: 12762813]

11. Valdés LJJ III, Chang HM, Visger DC, Koreeda M. Salvinorin C, a New Neoclerodane Diterpene from a Bioactive Fraction of the Hallucinogenic Mexican Mint Salvia divinorum. Org. Lett 2001;3:3935-3937. [PubMed: 11720573] We purified 9 by HPLC (40\% EtOAc/petrol).

12. Valdés, LJJ, III. PhD Thesis. University Of Michigan; Ann Arbor, MI: 1983. The Pharmacognosy Of Salvia Divinorum (Epling And Játiva-M): an Investigation of Ska Maria Pastora (Mexico). (a) p. 198-200.(b) p. 166-167.

13. Brown, L. PhD Thesis. University of Michigan; Ann Arbor, MI: 1984. The Stereocontrolled Synthesis of Optically Active Vitamin E Side Chains. II. Benzoyl Triflate and its Application in the Determination of the Absolute Configuration of Divinorin A and B, and Terrecyclic acid. (a) p. 202 (b) p. 73-75.(c) p. 196(d) p. 208 In our hands, reduction of the lactone (DIBALH in THF) did not go to completion at $-78{ }^{\circ} \mathrm{C}$; and although warming to $-40{ }^{\circ} \mathrm{C}$ forced the reaction to completion, yield was not improved due to side reactions. See Supporting Information for our results and full characterization data.

14. Tidgewell K, Harding WW, Schmidt M, Holden KG, Murry DJ, Prisinzano TE. A facile method for the preparation of deuterium labeled salvinorin A: synthesis of $\left[2,2,2-{ }^{2} \mathrm{H}_{3}\right]$-salvinorin A. Bioorg. Med. Chem. Lett 2004;14:5099-5102. [PubMed: 15380207]PMID: 15380207 It should be noted that the title compound, a more accurate name for which would be $\left(\right.$ acetyl $\left.-{ }^{2} \mathrm{H}_{3}\right)$ salvinorin A, was previously reported by Brown. ${ }^{13 \mathrm{~d}}$

15. Koreeda M, Brown L, Valdés LJJ III. The Absolute Stereochemistry of Salvinorins. Chem. Lett 1990:2015-2018.

16. Valdés LJJ III. Salvia-Divinorum and the Unique Diterpene Hallucinogen, Salvinorin (Divinorin)A. J. Psychoact. Drugs 1994;26:277-283.PMID: 7844657

17. Strazzolini P, Giumanini AG, Cauci S. Acetic formic anhydride. Tetrahedron 1990;46:1081-1118.

18. Kraus GA, Frazier KA, Roth BD, Taschner MJ, Neuenschwander K. Conversion of lactones into ethers. J. Org. Chem 1981;46:2417-2419.

19. Hansen MC, Verdaguer X, Buchwald SL. Convenient Two-Step Conversion of Lactones into Cyclic Ethers. J. Org. Chem 1998;63:2360-2361.

20. Kelly TR, Dali HM, Tsang WG. Lithium thiomethoxide: a convenient mercaptide reagent. Tetrahedron Lett 1977:3859-3860.

21. Sutherland, AG. One or More CH Bond(s) Formed by Substitution: Reduction of C-Halogen and CChalcogen Bonds. In: Roberts, SM., editor. Comprehensive Organic Functional Group Transformations. Vol. 1st ed. Vol. Vol. 1. Pergamon; Oxford: 1995. p. 1-26.

22. Kanemitsu K, Tsuda Y, Haque ME, Tsubono K, Kikuchi T. Reaction of cyclic thioxocarbonates with tributyltin hydride. Chem. Pharm. Bull 1987;35:3874-3879.

23. Siebert DJ. Localization of Salvinorin A and Related Compounds in Glandular Trichomes of the Psychoactive Sage, Salvia divinorum. Ann. Bot 2004;93:763-771. [PubMed: 15087301]

24. Bigham AK, Munro TA, Rizzacasa MA, Robins-Browne RM. Divinatorins A-C, New Neoclerodane Diterpenoids from the Controlled Sage Salvia divinorum. J. Nat. Prod 2003;66:1242-1244. [PubMed: 14510607] 


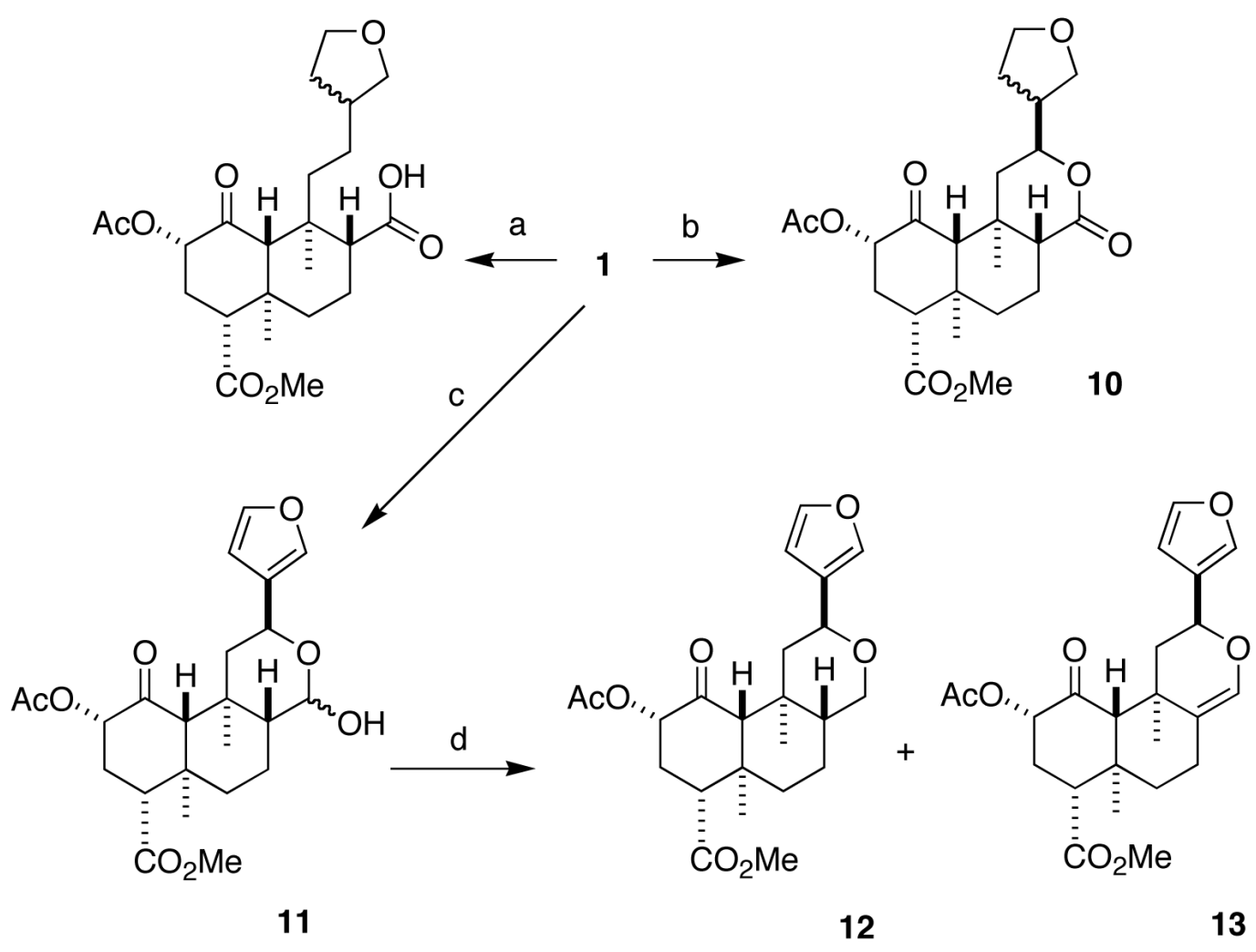

Scheme 1.

${ }^{a}$ Reagents: (a) $\mathrm{H}_{2}$ (1 atm), $\mathrm{Pd} / \mathrm{C}(5 \%), \mathrm{MeOH}, \mathrm{rt}$; (b) $\mathrm{H}_{2}$ (4 atm), $\mathrm{Rh} / \mathrm{C}(5 \%), \mathrm{CH}_{2} \mathrm{Cl}_{2} / \mathrm{MeOH}$, rt; (c) DIBALH, THF, $-78{ }^{\circ} \mathrm{C}$; (d) $\mathrm{Et}_{3} \mathrm{SiH}, \mathrm{BF}_{3} \bullet \mathrm{Et}_{2} \mathrm{O}, \mathrm{CH}_{2} \mathrm{Cl}_{2}, 0{ }^{\circ} \mathrm{C}$. 


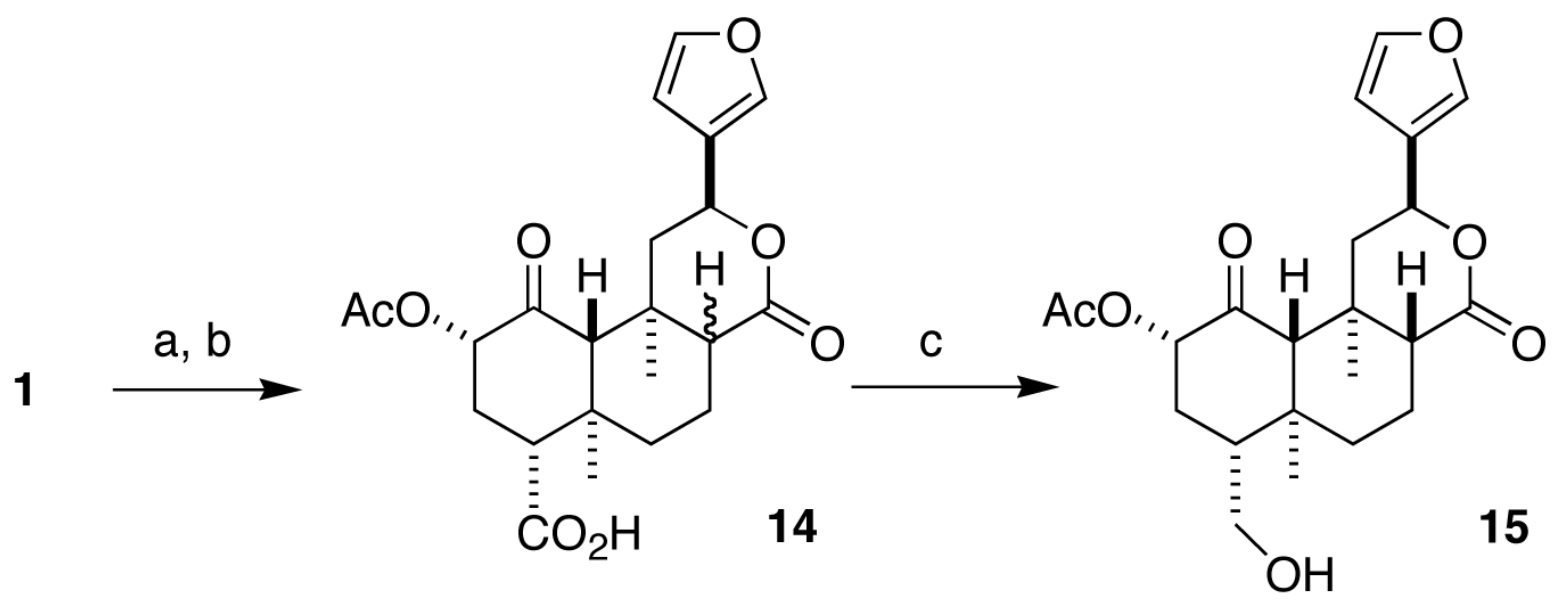<smiles>CO[C@H]1C[C@@H]2OC(=S)O[C@@H]2[C@H](C)[C@]1(C)[C@H]1C[C@H](c2ccoc2)OC(=O)[C@H]1C</smiles>

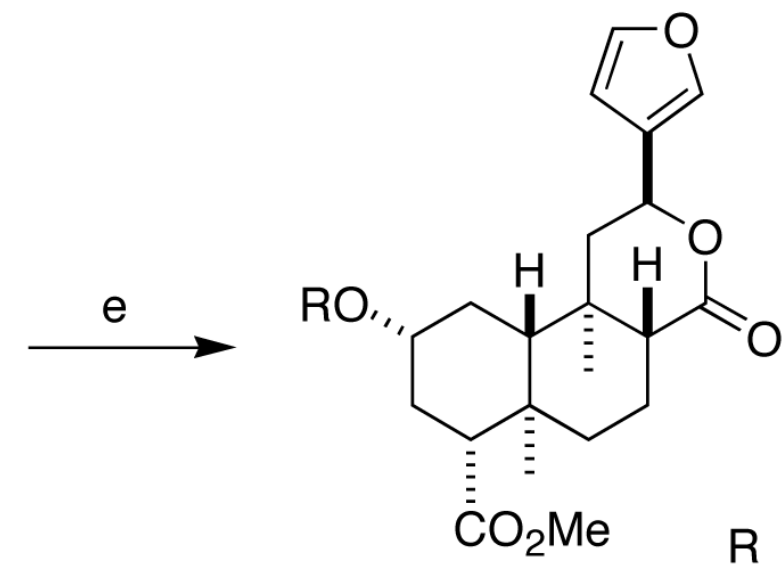

b

Scheme 2.

${ }^{a}$ Reagents: (a) LiSEt, DMPU, $55^{\circ} \mathrm{C}$; (b) $\mathrm{Ac}_{2} \mathrm{O}$, DMAP, pyridine, rt; (c) $\mathrm{BH}_{3}$, THF, $55^{\circ} \mathrm{C}$; (d)

Thiocarbonyldiimidazole, DMF, $90^{\circ} \mathrm{C}$; (e) $\mathrm{Bu}_{3} \mathrm{SnH}, \mathrm{AIBN}$, toluene, $80^{\circ} \mathrm{C}$. 


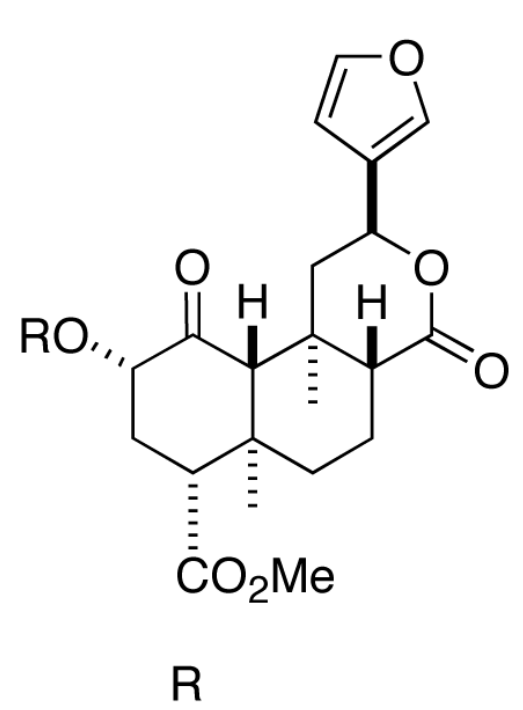

$\begin{array}{ll}1 & \mathrm{Ac} \\ 2 & \mathrm{H} \\ 3 & \mathrm{CHO}\end{array}$

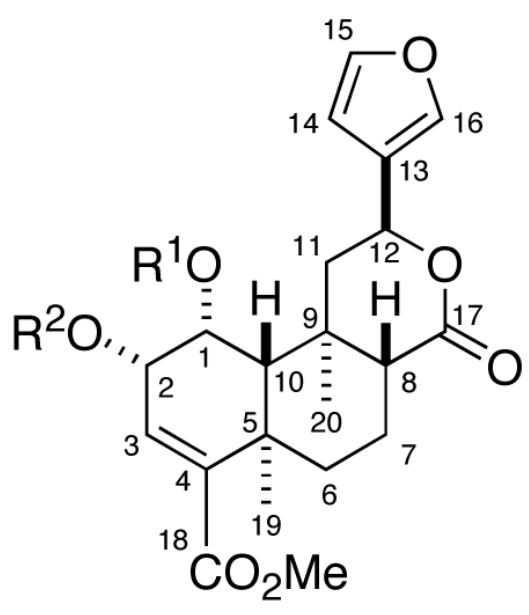

$R^{1} \quad R^{2}$

4 Ac $\mathrm{H}$

$5 \mathrm{H} \quad \mathrm{Ac}$

6 Ac Ac

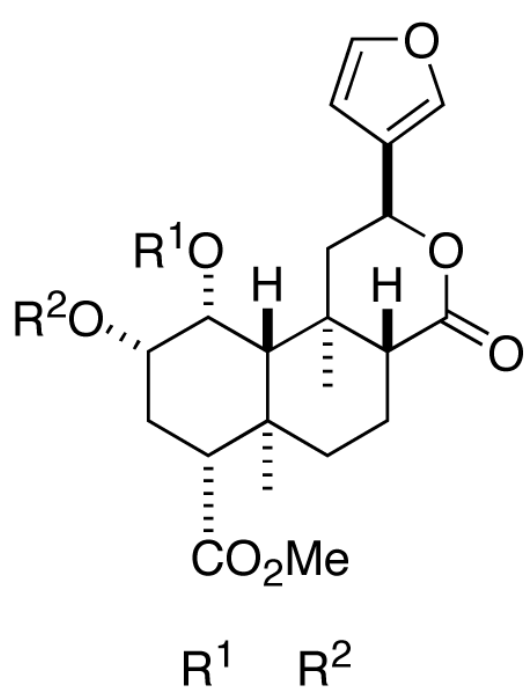

$7 \mathrm{H} \quad \mathrm{H}$

$8 \mathrm{H} \quad A C$

$9 A C A C$

Figure 1. 
Table 1

Binding Affinities $^{a}$ and Functional Activities ${ }^{b}$ at Cloned KORs

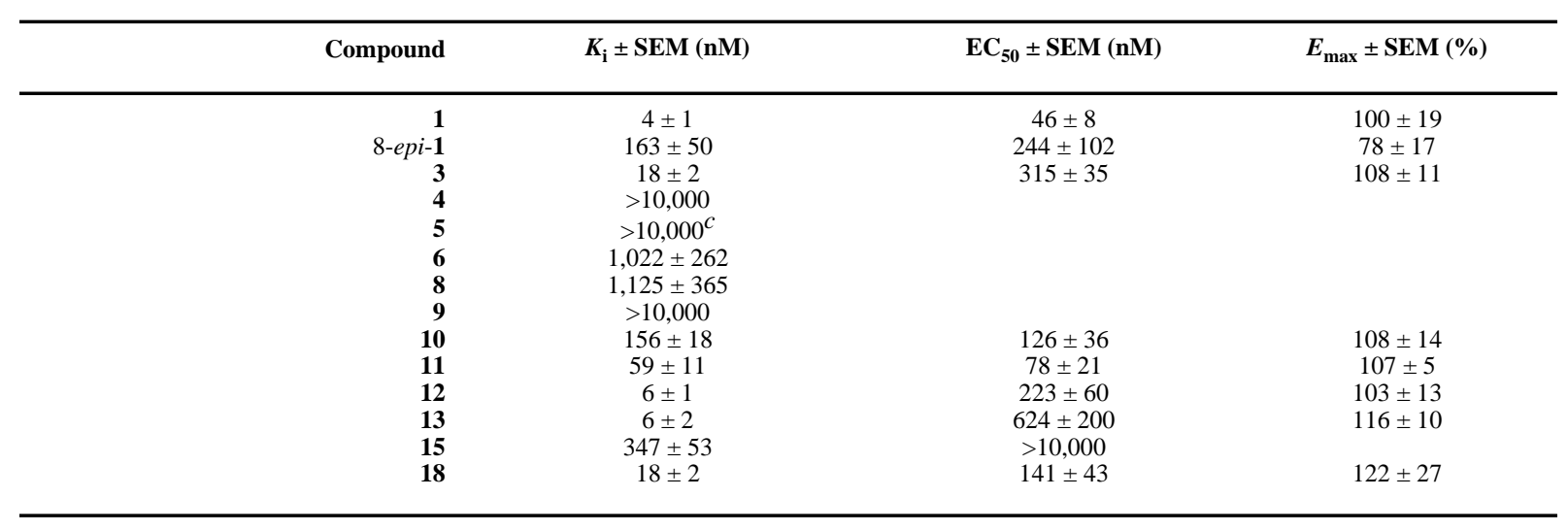

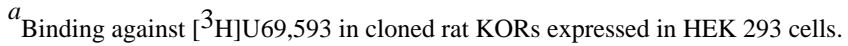

${ }^{b}$ Intracellular $\mathrm{Ca}^{2+}$ mobilization.

${ }^{c}$ Against $\left[{ }^{3} \mathrm{H}\right]$ diprenorphine. 